J. Lake Sci. (湖泊科学), 2010, 22(1): 86-92

http: //www. jlakes.org. E-mail: jlakes@niglas.ac.cn

(c) 2010 by Journal of Lake Sciences

\title{
松花江哈尔滨段水域硅藻植物群落及其水质的初步评价"
}

\author{
栾 卓, 范亚文 ${ }^{* *}$, 门晓宇 \\ (哈尔滨师范大学生命科学与技术学院,哈尔滨 150025)
}

\begin{abstract}
摘 要: $2005-2006$ 年 5-9 月、12 月的两年间,在松花江哈尔滨段水域进行了硅藻植物的调查采集,经观察鉴定,共发现 硅藻植物 72 种 43 变种 3 变型, 分别隶属于 2 纲 6 目 9 科 23 属, 共计 118 个分类单位. 本文对松花江哈尔滨段水域的环 境特征, 硅藻植物群落组成、种类丰度的季节性变化进行了研究, 利用硅藻植物与环境相关性特点对水质进行了初步评 价. 研究结果表明松花江段哈尔滨水域的硅藻植物群落, 总体来说以普生种类 (共计 86 个分类单位) 为每年的常见种类, 还有一些嗜碱种类和冷水种类出现; 硅藻种类的丰度随季节变化明显, 从夏季到秋季逐渐增多. 硅藻的群落结构变化主 要受 $\mathrm{pH}$, 温度, $\mathrm{TN}, \mathrm{BOD}_{5}$, 氨氮的影响, 从优势种的组成来看, $\beta$-中污以上的污水指示种类数量最多,一些富营养化种类和 耐污种类也有出现,说明 $2005-2006$ 年松花江流域水质污染呈中度至重度污染.
\end{abstract}

关键词: 硅藻植物;群落结构;松花江哈尔滨段水域;水质评价

\section{Environmental quality evaluation of Songhua River in Harbin using diatom assemblages}

LUAN Zhuo, FAN Yawen \& MEN Xiaoyu

(College of Life Science and Technology, Harbin Normal University, Harbin 150025, P. R. China)

Abstract : During May to September and December in 2005 -2006, the diatom communities were investigated in four sampling stations from Songhua River, Harbin. A total of 118 taxa were identified, belonging to 2 classes, 6 orders, 9 families, 23 genera, 72 species, 43 varieties and 3 forms. The environmental characteristics of Songhua River, diatom communities, taxon richness and seasonal variables were examined. Water-quality parameters of Songhua River in Harbin during 2005 - 2006 were followed as: water pH $6.8-7.6$, TN $0.68-2.54 \mathrm{mg} / \mathrm{L}$, TP $0.05-0.18 \mathrm{mg} / \mathrm{L}$, DO $6.45-6.8 \mathrm{mg} / \mathrm{L}$, BOD $_{5} 0.68-3.12 \mathrm{mg} / \mathrm{L}, \mathrm{COD}$ $13.60-18.30 \mathrm{mg} / \mathrm{L}, \mathrm{NH}_{3}-\mathrm{N} 0.11-1.52 \mathrm{mg} / \mathrm{L}$. The dominant species were Gomphonema angustatum, Cyclotella meneghiniana, Cymbella minuta var. pseudogracilis, Melosira granulate etc. Most of taxa (86 taxa) was cosmopolitan, and alkalescent taxa ( $G y$ rosigma acuminatum, Pinnularia gibba etc. ) and cold water taxa (Gomphonema olivaceum, Eunotia valida etc. ) were also found. The diatom richness changed with seasons obviously, diatom species were higher in autumn than that in summer. Temperature, $\mathrm{pH}, \mathrm{TN}, \mathrm{BOD}_{5}$ and $\mathrm{NH}_{3}-\mathrm{N}$ were the main factors affecting the diatom assemblages. The abundance of $\beta$-mesosaprobic taxa were most in dominant diatom, which indicated that water quality of Songhua River in Harbin were mesosaprobic to pollutional water seriously.

Keywords: Diatom assemblages; Songhua River, Harbin; environmental quality evaluation

硅藻作为单细胞藻类在河流、湖泊的多样性研究中始终扮演着重要的角色, 硅藻植物群落对水环境变 化非常敏感, 对所处环境的变化会产生迅速的反应 ${ }^{[1]}$. 硅藻植物属、种及其群落组成特征在指示和监测水体 的营养变化,湖泊营养演化研究上的重要性已被大量的湖沼学研究结果所证实 ${ }^{[24]}$. 不同种类的硅藻对水质 的适应能力各不相同,当水体属性改变时,生活在这些水体中的硅藻群体会产生相应的变化,或繁盛、或衰 亡、或被新的硅藻群体所替代, 硅藻的这一特性已成为对江河、湖泊等水体质量监测的重要依据, 目前利用

* 国家自然科学基金项目 (30570123, 30870157)、黑龙江省教育厅项目 (11521062) 和黑龙江省普通高等学校骨干 教师创新能力资助计划项目 (1055G018) 联合资助. 2009-05-04 收稿; 2009-09-07 收修改稿. 奕卓, 1982 年 生, 硕士.

** 通讯作者;E-mail:fanyaw@yahoo.com. cn. 
硅藻的指示作用监测水质的污染情况进而评价流动水体的生物监测方法已得到广泛应用 ${ }^{[2]}, 2000$ 年欧盟水 框架指导委员会 (Water Framework Directive of the European Union) 已将硅藻推荐为当前水环境整治决策中 可以用来确定营养水平的一个行之有效的生物指标 ${ }^{[3]}$. 与国外开展的研究工作相比, 我国利用硅藻植物群 落进行环境监测和评价的研究工作起步较晚, 有一些学者在近几年已开始利用硅藻植物对水域变化进行了 相应的研究 ${ }^{[4-5]}$.

哈尔滨市位于东经 $125^{\circ} 42^{\prime}-130^{\circ} 10^{\prime}$, 北纬 $44^{\circ} 04^{\prime}-46^{\circ} 40^{\prime}$ 之间, 地处中国东北北部地区, 松花江哈尔滨 干流西自双城市人境, 城市段从朱顺屯至大顶子山约 $66 \mathrm{~km}$, 其流域位于北方寒冷地区, 水量变化具有明显的 季节性特征, 在不同的环境条件下, 藻类植物群落呈现出一定的变化. 松花江水域的理化和部分生物指标的 数据虽由各级环境保护部门逐年进行监测, 但有关该水域中主要生物成员一一藻类的资料却知之甚少 ${ }^{[6]}$. 本文对松花江哈尔滨段硅藻植物群落、环境特点及其硅藻与环境相关性进行了初步探讨, 利用硅藻种类的 指示作用对松花江哈尔滨段水域进行初步评价, 为松花江的综合治理及环境保护提供基础的生物学资料.

\section{1 材料和方法}

\section{1 样品采集与鉴定}

$2005-2006$ 年的 5-9 月、12 月, 在松花江 哈尔滨段共设 4 个采集断面, 其位置分别在松花 江哈尔滨段干流的朱顺屯、阿什河口下、呼兰河 口下和大顶子山,左右近岸处各设一个采样点, 4 个采集点 $(\mathrm{S} 1-\mathrm{S} 4)$ 位置如图 1 所示. 对松花江 的 4 个采集断面进行硅藻样本的采集, 浮游及着 生硅藻标本的采集按常规方法进行 ${ }^{[7]}$, 每个采集 点采集标本 $2-3$ 次, 将采集好的标本注人标本 瓶, 用鲁格固定液 (lugol solution) 保存、固定、摇 匀即可. 硅藻样品采用常规酸处理方法, 制成硅 藻永久标片 ${ }^{[7]}$. 标本观察鉴定在 Olympus BH-2 光学显微镜 $(10 \times 100)$ 负相差下进行, 硅藻的鉴

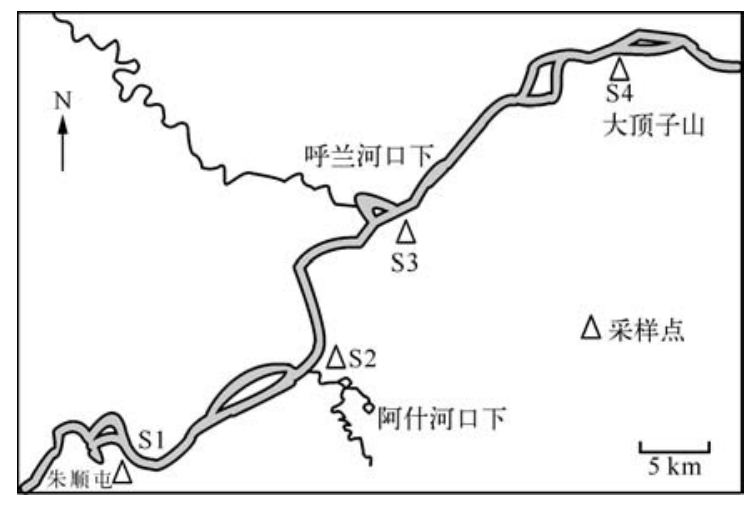

图 1 松花江哈尔滨段采样点示意图

Fig. 1 Distribution of sampling sites in Songhua River, Harbin 定主要依据 Hustedt ${ }^{[8-9]}$, Patrick \& Reimer ${ }^{[10]}$, Krammer ${ }^{[11]}$, Langela-Bertalot $\mathrm{H}^{[12]}$ 等有关文献.

\section{2 环境数据测定}

在松花江哈尔滨段 4 个采集断面进行硅藻标本采集的同时, 测定水体温度、 $\mathrm{pH}$ 值, 并在 $24 \mathrm{~h}$ 之内测定 $\mathrm{BOD}_{5}, \mathrm{COD}, \mathrm{TN}, \mathrm{TP}$, 溶解氧等理化指标, 主要测定方法依据水和废水监测等常规分析方法 ${ }^{[13-14]}$.

\section{2 结果}

\section{1 硅藻的种类组成及丰度变化}

松花江哈尔滨段的硅藻植物种类比较丰富, 经鉴定已发现的硅藻植物共有 118 个分类单位,包括 72 种 43 变种 3 变型, 分别隶属于 2 纲 6 目 9 科 23 属. 对松花江哈尔滨段水域的硅藻植物丰度进行分析 (丰度图 前期处理: 选择至少在两个或两个以上样品中出现, 且含量在每个样品中超过 $1 \%$ 以上的属种用于数据库的 分析), 可以明显看出两年间各采样点在不同季节硅藻植物的丰度变化 (图 2).

$2005-2006$ 年期间的夏、秋季, 在 S1 和 S2 采样点中, 硅藻植物均以窄异极藻 (Gomphonema angustatum (Kütz.) Rabh)、颗粒直链藻 (Melosira granulate (Ehr.) Ralf) 和梅尼小环藻 (Cyclotella meneghiniana Kütz.) 等 为优势种群, 在 S3 采样点中, 则以杰森舟形藻 (Navicula Jentzschii Grun.) 、窄异极藻和弓形舟形藻埃斯坎比 亚变种 (Navicula schroeteri var. escambia Patr.) 等为优势种群, 在 S4 采样点中, 杰森舟形藻、肘状针杆藻 (Synedra ulna (Nitzsch) Ehr.) 等是夏、秋季的优势种群; 而在冬季,4 个采集断面多以强壮短缝藻 (Eunotia valida Hust. ) 和梅尼小环藻等种群占优势地位.

2005 年的硅藻群落种类组成与 2006 年有一定的差异, 这与两年间环境条件的不同有一定的相关性. 在 


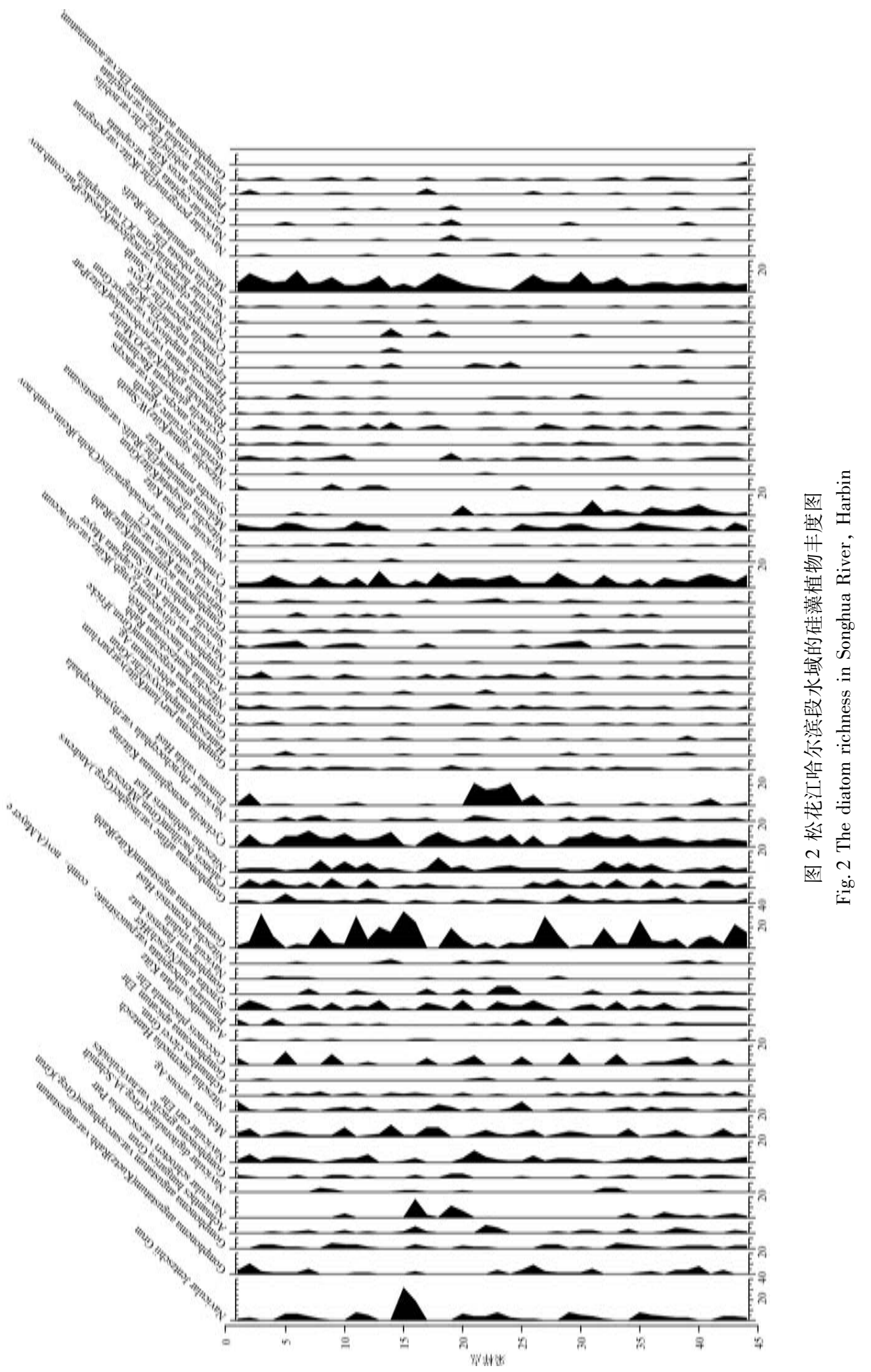


藻类组成方面窄异极藻、强壮短缝藻、带状菱形藻 (Nitzschia fasciculata Grun.) 和尖针杆藻 (Synedra acus Kütz. ) 等分类单位在 2005 年的丰度明显高于 2006 年. 2006 年的硅藻植物群落, 除了窄异极藻、颗粒直链藻 等仍然保持优势地位外, 还增加了微小桥弯藻伪纤细变种 (Cymbella minuta var. pseudogracilis Reim.) 和扁圆 卵形藻 (Cocconeis placentula Ehr.) 等分类单位, 除此以外各采样点优势群落变化不明显.

\section{2 松花江哈尔滨段水域的环境特征}

$2005-2006$ 年采集期间, 我们对设置在松花江哈尔滨段水域的 4 个采集地, 即朱顺屯 (S1)、阿什河口下 (S2)、呼兰河口下 $(S 3)$ 和大顶子山 $(S 4)$ 的各项环境参数进行了常规方法测定,其结果见表 1 .

松花江哈尔滨段水域四季分明, 温度变化差异较大, 高温天气集中在 6-8 月份, 9 月略有降低, 低温在 12 月份, 是全年温度最低的季节; 两年间的 $\mathrm{pH}$ 值在各个月份比较平稳, 没有太大的起伏 (6.8-7.6 之间), 江水略呈碱性; 在整个春季 $\mathrm{pH}$ 值一直保持弱碱性, 波动的范围在 7.1-7.5 之间. 2005-2006 年期间, 松花 江哈尔滨段水域总氮在 $0.68-2.54 \mathrm{mg} / \mathrm{L}$ 之间变化, 总磷的波动范围在 $0.05-0.18 \mathrm{mg} / \mathrm{L}$ 之间, DO 的波动范 围在 $4.45-6.8$ 之间, $\mathrm{BOD}_{5}$ 的波动范围在 $1-4 \mathrm{mg} / \mathrm{L}$ 之间, $\mathrm{COD}$ 值的波动范围在 $13.60-18.30 \mathrm{mg} / \mathrm{L}$ 之间, 氨氮的波动范围在 $0.11-1.52 \mathrm{mg} / \mathrm{L}$ 之间. 从理化指标来看, $2005-2006$ 年松花江流域水质污染已经比较 严重, 主要污染特征呈有机型污染, 主要污染指标为氨氮、总磷和化学需氧量 $(13.60-18.30 \mathrm{mg} / \mathrm{L})($ 表 1$)$.

\section{3 硅藻植物群落与环境因子的相关性}

硅藻作为单细胞藻类, 其群落结构在江河、湖泊中呈多样性的分布变化, 其分布特征对于评价水域的健 康状况尤为重要, 而大部分硅藻种类具有较窄的环境适应度, 因此硅藻植物在不同环境的出现, 可以作为环 境监测与评价的一个重要的生物指标 ${ }^{[15]}$.

松花江哈尔滨段水域的硅藻植物群落, 总体来说以普生种类 (共计 86 个分类单位) 为每年的常见种类, 同时该水域还出现尖布纹藻 (Gyrosigma acuminatum (Kütz.) Rabh.)、弯羽纹藻 (Pinnularia gibba Ehr.) 、普 通等片藻 (Diatoma vuigare Bory.) 等碱性种类, 这与松花江水域酸碱度偏碱的特征是相一致的.

在采样期间, 松花江哈尔滨段水域还出现了一些冷水种, 如橄榄绿异极藻, 强壮短缝藻等; 松花江哈尔 滨段水域的硅藻植物在不同的采集地也出现了相应的生物指示种类, 如 $\beta$-中污以上的污水指示生物卵圆双 眉藻 (Amphora ovalis Kütz.) 、棍形美壁藻 (Caloneis bacillum (Grun.) Meresch)、普通等片藻( Diatoma vulgare Bory. ), 缢缩异极藻 (Gomphonema constrictum Ehr.) 和尖针杆藻等.

此外我们在松花江哈尔滨段还发现了一些富营养化的种类, 如颗粒直链藻、卵形双菱藻羽纹变种 ( Surirella ovata var. pinnata (W. Smith) Hust.) 及窄异极藻等, 颗粒直链藻、窄异极藻几乎在所有采集断面都 有发现, 且多出现在春秋两季.

\section{3 讨论与结论}

江河水域中的硅藻植物群落组合与生态环境的地域特点具有高度的相关性, 而硅藻种类在分布地区的 丰度、分布广度以及群落结构特点都可揭示所处环境的生物地理特点 ${ }^{[16]} .2005-2006$ 年两年期间, 松花江 哈尔滨段硅藻植物的优势种群为窄异极藻、梅尼小环藻、微小桥弯藻伪纤细变种、颗粒直链藻等, 这些种类 在所有采样点中均有出现且丰度较高, 同时, 硅藻种类的丰度随季节变化明显, 由夏到秋季逐渐增多, 夏季 多以梅尼小环藻、扁圆卵形藻等为优势种群, 秋季各采集地优势种群虽略有差别, 但窄异极藻、颗粒直链藻 等种群多以较高的丰度几乎出现在所有的采集点中. 可以说, 环境因素是造成这种变化的主要原因, 即不同 季节, 水体的温度、光照、溶解氧、营养盐水平等均有差异, 而不同的种类对环境条件的适应情况也随之发生 变化, 因而造成了硅藻植物分布的季节性变化 ${ }^{[17]}$. 一般情况下, 夏季由于营养物的大量消耗及其它动物的 吞食, 硅藻种类数量进人低谷, 秋季则逐渐升高, 松花江哈尔滨段水域的硅藻植物群落的结构特点也反映了 松花江水域的生态环境变化.

随着季节的变化, 水体温度是影响硅藻群落的重要因素, 硅藻和水温这种明显的相互关系在不同的采 集点中均可发现, 如夏季 (温度在 $23-26^{\circ} \mathrm{C}$ ), 在阿什河口下, 呼兰河口下和大顶子山的采集断面, 硅藻种类 多以一些暖水种如: 纤细异极藻舟形变种 (Gomphonema gracile var. naviculoides)、侧生窗纹藻象鼻变种 (Epithemia adnata var. proboscidea) 、扁圆卵形藻、梅尼小环藻等大量出现, 其中, 梅尼小环藻是比较典型耐高温的 
富营养种类 ${ }^{[18]}$, 而在 $2005 、 2006$ 年冬季 (温度在 $2.9-3.5^{\circ} \mathrm{C}$ 变化), 硅藻组合以一些冷水种如强壮短缝藻、 尖异极藻、橄榄绿异极藻等种群为主.

表 $12005-2006$ 年间松花江哈尔滨段水域环境参数

Tab. 1 Water-quality indices of Songhua River in Harbin in 2005 - 2006

\begin{tabular}{|c|c|c|c|c|c|c|c|c|c|}
\hline 采样点 & $\begin{array}{l}\text { 溶解氧 } \\
(\mathrm{mg} / \mathrm{L})\end{array}$ & $\begin{array}{c}\text { 氨氮 } \\
(\mathrm{mg} / \mathrm{L})\end{array}$ & $\begin{array}{c}\text { 总氮 } \\
(\mathrm{mg} / \mathrm{L})\end{array}$ & $\begin{array}{c}\text { 总磷 } \\
(\mathrm{mg} / \mathrm{L})\end{array}$ & $\mathrm{pH}$ & 温度 $\left({ }^{\circ} \mathrm{C}\right.$ ) & $\begin{array}{c}\mathrm{BOD}_{5} \\
(\mathrm{mg} / \mathrm{L})\end{array}$ & $\begin{array}{c}\text { COD } \\
(\mathrm{mg} / \mathrm{L})\end{array}$ & 采集时间 \\
\hline S1 & 5.16 & 0.52 & 0.78 & 0.16 & 7.0 & 14 & 1.67 & 13.9 & 2005.05 \\
\hline S2 & 6.42 & 0.93 & 1.14 & 0.15 & 7.2 & 15 & 2.13 & 13.5 & 2005.05 \\
\hline S3 & 5.40 & 0.11 & 0.69 & 0.16 & 7.1 & 14 & 2.16 & 15.3 & 2005.05 \\
\hline S4 & 5.28 & 0.35 & 1.25 & 0.18 & 7.1 & 15 & 2.30 & 17.3 & 2005.05 \\
\hline S1 & 6.24 & 0.36 & 1.44 & 0.14 & 7.1 & 19 & 1.35 & 13.8 & 2005.06 \\
\hline S2 & 6.28 & 0.96 & 1.51 & 0.15 & 7.1 & 20 & 1.35 & 13.6 & 2005.06 \\
\hline S3 & 5.44 & 0.96 & 1.24 & 0.15 & 7.3 & 22 & 1.78 & 18.3 & 2005.06 \\
\hline S4 & 5.92 & 0.45 & 0.80 & 0.13 & 7.1 & 23 & 2.16 & 16.2 & 2005.06 \\
\hline S1 & 4.46 & 0.30 & 1.30 & 0.16 & 7.4 & 25 & 2.30 & 14.7 & 2005.07 \\
\hline S2 & 6.69 & 0.70 & 0.94 & 0.17 & 7.2 & 23 & 1.35 & 15.3 & 2005.07 \\
\hline S3 & 5.99 & 0.57 & 0.68 & 0.18 & 7.1 & 24 & 3.14 & 13.8 & 2005.07 \\
\hline S4 & 6.80 & 1.20 & 1.30 & 0.12 & 7.1 & 24 & 3.11 & 16.1 & 2005.07 \\
\hline S1 & 6.47 & 0.75 & 1.46 & 0.14 & 7.2 & 26 & 0.68 & 13.6 & 2005.08 \\
\hline S2 & 6.01 & 0.52 & 0.98 & 0.14 & 7.1 & 24 & 1.23 & 17.2 & 2005.08 \\
\hline S3 & 5.83 & 0.67 & 1.21 & 0.16 & 7.2 & 23 & 1.34 & 13.9 & 2005.08 \\
\hline S4 & 5.94 & 0.82 & 2.10 & 0.14 & 7.4 & 26 & 0.89 & 16.8 & 2005.08 \\
\hline S1 & 6.64 & 0.70 & 1.33 & 0.09 & 7.3 & 18 & 0.69 & 13.2 & 2005.09 \\
\hline S2 & 5.83 & 0.58 & 1.45 & 0.15 & 7.2 & 19 & 1.35 & 18.1 & 2005.09 \\
\hline S3 & 5.79 & 0.76 & 0.91 & 0.13 & 7.2 & 21 & 1.33 & 15.6 & 2005.09 \\
\hline S4 & 5.91 & 0.92 & 1.36 & 0.14 & 7.4 & 18 & 1.78 & 14.9 & 2005.09 \\
\hline S1 & 6.71 & 0.68 & 1.56 & 0.12 & 7.0 & 2.9 & 0.74 & 13.2 & 2005.12 \\
\hline S2 & 6.35 & 1.52 & 1.67 & 0.15 & 6.8 & 3.2 & 1.24 & 13.6 & 2005.12 \\
\hline S3 & 4.68 & 0.88 & 1.98 & 0.17 & 6.8 & 2.8 & 1.23 & 18.4 & 2005.12 \\
\hline S4 & 5.24 & 1.39 & 2.51 & 0.16 & 6.7 & 3.5 & 0.92 & 14.3 & 2005.12 \\
\hline S1 & 5.20 & 0.52 & 0.80 & 0.17 & 7.1 & 13 & 1.68 & 13.8 & 2006.05 \\
\hline S2 & 6.46 & 0.92 & 1.12 & 0.14 & 7.0 & 14 & 2.12 & 13.5 & 2006.05 \\
\hline S3 & 5.48 & 0.71 & 1.11 & 0.16 & 7.2 & 14 & 2.17 & 15.7 & 2006.05 \\
\hline S4 & 5.29 & 0.33 & 1.23 & 0.18 & 7.1 & 15 & 2.30 & 17.3 & 2006.05 \\
\hline S1 & 6.27 & 0.36 & 1.46 & 0.15 & 7.2 & 20 & 1.35 & 13.9 & 2006.06 \\
\hline S2 & 6.26 & 0.98 & 1.52 & 0.15 & 7.1 & 21 & 1.33 & 13.6 & 2006.06 \\
\hline S3 & 5.43 & 1.10 & 1.24 & 0.14 & 7.3 & 22 & 1.78 & 18.2 & 2006.06 \\
\hline S4 & 5.93 & 0.46 & 0.82 & 0.13 & 7.1 & 24 & 2.17 & 16.3 & 2006.06 \\
\hline S1 & 4.45 & 0.40 & 1.33 & 0.16 & 7.5 & 25 & 2.30 & 14.7 & 2006.07 \\
\hline S2 & 6.72 & 0.68 & 1.10 & 0.18 & 7.2 & 24 & 1.35 & 15.3 & 2006.07 \\
\hline S3 & 5.98 & 0.57 & 0.69 & 0.17 & 7.2 & 24 & 3.15 & 13.8 & 2006.07 \\
\hline S4 & 6.82 & 1.23 & 1.33 & 0.12 & 7.1 & 24 & 3.11 & 16.2 & 2006.07 \\
\hline S1 & 6.35 & 0.76 & 1.68 & 0.14 & 7.2 & 23 & 2.98 & 17.9 & 2006.08 \\
\hline S2 & 5.39 & 0.95 & 2.10 & 0.09 & 7.0 & 23 & 2.13 & 16.1 & 2006.08 \\
\hline S3 & 6.38 & 0.68 & 2.17 & 0.14 & 7.1 & 25 & 1.99 & 14.8 & 2006.08 \\
\hline S4 & 6.71 & 0.96 & 2.30 & 0.08 & 7.1 & 24 & 1.86 & 17.1 & 2006.08 \\
\hline S1 & 6.27 & 0.90 & 1.53 & 0.05 & 7.3 & 22 & 1.56 & 18.2 & 2006.09 \\
\hline S2 & 5.92 & 0.75 & 1.90 & 0.09 & 7.4 & 20 & 2.34 & 14.1 & 2006.09 \\
\hline S3 & 6.64 & 0.83 & 1.89 & 0.12 & 7.4 & 21 & 3.12 & 13.6 & 2006.09 \\
\hline S4 & 6.72 & 1.02 & 2.12 & 0.04 & 7.5 & 22 & 2.19 & 16.2 & 2006.09 \\
\hline S1 & 6.70 & 0.69 & 1.58 & 0.11 & 7.0 & 2.7 & 0.84 & 14.2 & 2006.12 \\
\hline S2 & 6.36 & 1.51 & 1.69 & 0.16 & 7.6 & 2.8 & 1.26 & 17.4 & 2006.12 \\
\hline S3 & 4.69 & 0.89 & 1.99 & 0.16 & 7.7 & 2.9 & 1.33 & 14.6 & 2006.12 \\
\hline S4 & 5.26 & 1.39 & 2.54 & 0.17 & 7.3 & 3.3 & 1.12 & 15.3 & 2006.12 \\
\hline
\end{tabular}


水体 $\mathrm{pH}$ 值的变化, 尤其在偏碱性水域的变动是影响环境变化的重要因子, 进而改变硅藻植物的群落结 构. 硅藻植物群落对水体 $\mathrm{pH}$ 的反应很敏感, 而且大部分硅藻种类都对 $\mathrm{pH}$ 值具有较窄的耐受范围, 因此水 体 $\mathrm{pH}$ 的改变会对硅藻分布及组成造成很大影响 ${ }^{[18]}$. 松花江哈尔滨段水域的 $\mathrm{pH}$ 值几乎常年处于 7.1-7.5 之间, 并有逐年增高的趋势, 因此该水域出现大量适应碱性水体中生长的种类, 如: 弯棒杆藻 (Rhopalodia gib$b a$ )、卡里舟形藻 (Navicula cari) 和微绿舟形藻 (Navicula viridula) 等, 其中 2006 年出现的嗜碱种——卡里舟 形藻丰度明显高于 2005 年.

藻类植物作为水体环境的指示植物和水域监测的综合指标, 能对水质变化迅速做出反应, 从而可作为 评价河流受污染程度和受人类活动干扰程度的重要生物监测指标. 由于硅藻植物群落组成非常复杂, 对环 境变化及其敏感, 且硅藻的许多种类能够很好地表现它们所生活的水体特征, 由此提供了相关的生态信息 特征 ${ }^{[19]} .2005-2006$ 年松花江哈尔滨段硅藻植物的优势种以塞污带至中污带种类居多, 从优势种的组成来 看, $\beta$-中污以上的污水指示生物种类数最多, 如: 卵圆双眉藻、螺形美壁藻、普通等片藻、缢缩异极藻、尖针杆 藻等, 它们多出现在阿什河口下和呼兰河口下两个采样点, 朱顺屯和大顶子山采样点也偶有出现.

值得一提的是, 2005 年 11 月初, 中石油吉化公司的硝基苯储蓄罐爆炸后, 约有 100 多吨的苯类污染物 进人松花江, 造成重特大污染, 因此, 在 2005 年的 12 月及 2006 年 5-9,12 月, 我们分别对松花江哈尔滨段 水域都进行了藻类标本采集, 经研究发现, 2005-2006 年有一些中富营养化至富营养的种类如: 颗粒直链 藻、卵形双菱藻羽纹变种、窄异极藻、小型异极藻等在阿什河口下、呼兰河口下和大顶子山的采样点中均有 出现, 而且这些采样点的 $\mathrm{BOD}_{5} 、 \mathrm{COD}$ 值都比较高, 说明这些采样点的水质均有一定程度的污染. 其中一些 中营养化及耐污种类如: 窄异极藻, 尖针杆藻等分类单位在 2005 年的丰度明显高于 2006 年的丰度, 在 2005 年 12 月份, 呼兰河口下 (S3) 发现的耐污种两尖菱板藻较大变种 (Hantzschia amphioxys var. major Grun.) 的 丰度要明显高于其它月份, 从硅藻群落的分布及群落组成不难看出, 2005 年出现的耐污种类的丰度要高于 2006 年, 说明 2005 年松花江哈尔滨段水域的有机污染比 2006 年要严重一些, 这也与当时水域测定的各项 理化指标相一致.

许多研究表明, 不同水环境的营养水平对硅藻植物群落的分布具有较大的影响. 在我们的研究中, 硅藻 植物群落结构的变化主要受 $\mathrm{pH} 、$ 温度、TN、BOD $、$ 氨氮的影响, 占环境变化的主要因素, 这些环境因素也是 引起水质变化的主要原因. 呼兰河口下和大顶子山采集断面, 多出现颗粒直链藻极狭变种螺旋变型 (Melosira granulata var. angustissima fo. spiralis)、头状菱形藻、针形菱形藻等种类, 这些种类也常出现在总氮含量比 较高的水环境中 ${ }^{[20]}$.

尽管松花江哈尔滨段水域有一定程度的有机污染, 但在本研究的两年间, 朱顺屯和大顶子山采样点也 出现了一些寡污-清水指示生物种类, 如: 披针形曲壳藻 (Achnanthes lanceolata Bréb.)、喙头舟形藻 (Navicula rhynchocephala 、、弯羽纹藻等, 虽未形成优势群落, 但也说明松花江哈尔滨段水域在一定的时间和分布范围 内, 由于江水的流动和自净作用, 其水体的有机污染有了一定程度的降解, 进一步表明了硅藻植物群落结构 与环境特征的密切相关.

总的来看,在 $2005-2006$ 年两年间, 松花江哈尔滨水域的四个采集断面: 朱顺屯和大顶子山断面存在中 度的污染, 而阿什河口下和呼兰河口下存在比较严重的污染. 通过对松花江哈尔滨水域硅藻植物群落组成 及其分布特征的研究, 表明硅藻植物群落结构在监测松花江哈尔滨段水域水环境变化或富营养化的过程中 具有一定的指示作用, 可为今后松花江的水环境保护及环境监测提供重要的生物学数据.

致谢: 哈尔滨环境监测站在本文标本采集的过程中给予了大力的支持和帮助, 本文部分数据分析得到中国 科学院南京地理与湖泊研究所羊向东博士的大力支持, 作者在此表示最诚挚的谢意!

\section{4 参考文献}

[ 1 ] Round FE, Crawford RM, Mann DG. The diatoms, biology \& morphology of the genera. Cambridge: Cambridge University Press, 1990.

[ 2 ] Battegazzore M, Morisi A, Gallino B et al. Environmental quality evaluation of Alpine Springs in NW Italy using benthic diatoms. Diatom Research, 2004, 19(2) : 149-165.

[ 3 ] European Commission and the Parliament. Council Directive of the European Parliament and of the council 2000/60/EC. 
Establish a framework for community action in the field of water policy, 2000.

[ 4 ] Yang XD, Dong XH, GAO Guang et al. Relationship between surface sediment diatoms and summer water quality in shallow lakes of the middle and lower reaches of the Yangtze River. Journal of Integrative Plant Biology, 2005, 47(2) : 153164.

[5]董旭辉, 羊向东, 王 荣. 长江中下游地区湖泊富营养化的硅藻指示性属种. 中国环境科学, 2006, 26 (5): 570-574.

[6] 杨庆良，马 涛. 松花江(哈尔滨段) 水质分析与预测. 黑龙江水利科技, 2006, 34(1): 71-74.

[ 7 ] 胡鸿钧,魏印心. 中国淡水藻类系统、分类及生态. 北京: 科学出版社, 2006.

[ 8 ] Hustedt F. Die Süsswasser Flora Mitteleuropas. Heft 10: Bacillariophyta (Diatomeae). Jena: Gustav Fishcer, 1930.

[ 9 ] Hustedt F. Bacillariophyta (Diatomeae). A. Pascher. Diesusswasser-Flora Mitteleuropas. Jena: Gustav Fishcer, 1935 : 376-713.

[10] Patrick R, Reimer CW. The Diatoms of the United States. Philadelphia: Academy of Natural Sciences of Philadelphia, 1966, I: 295-643.

[11] Krammer K. Diatoms of the European Inland Waters and comparable Habitats, Vol. 1-2. FL 9491 Ruggell: A. R. G. Gantner Verlag K. G, 2002.

[12] Langela-Bertalot H. Diatoms of the European Inland Waters and comparable Habitats, Vol. 3. FL 9491 Ruggell: A. R. G. Gantner Verlag K. G, 2001.

[13］国家环境保护总局《水和废水监测分析方法》编辑委员会. 水和废水监测分析方法(第四版). 北京: 中国环境科 学出版社, 2002 .

［14］沈暳芬,章宗涉等. 微型生物监测新技术. 北京: 中国建筑工业出版社, 1990: 100-148.

[15] Gasse F. East African diatoms, taxonomy, ecological distribution. Bibliot Diatomol J Cramer, 1986, 11: 2101.

[16] Rimer F, Goma J, Cambra J et al. Benthic diatoms in western european streams with altitudes above $800 \mathrm{~m}$ : characterisation of the main assemblages and correspondence with ecoregions. Diatom Research, 2007, 22 (1) : 147-188.

[17] Thomnton KW, Kimmel BL, Payne FE. Reservoir limnology : ecological perspectives. New York: Wiley interscience Publication, 1990.

[18] Cox EJ. Identification of freshwater diatoms from live material. London: Chapman \& Hall, 1996.

[19] Soininen J. Environmental and spatial control of freshwater diatoms-A Review. Diatom Research, 2007,22 ( II) : $473-490$.

[20 ] Mihaela E, Yves TP. WA-PLS diatom-based $\mathrm{pH}$, TP and TOC inference models from 42 lakes in the Abitibi clay belt area (Quebec, Canada). Journal of Paleolimnology, 2002, 27: 151-170. 